\title{
Sublingual Powder Dosage Form
}

National Cancer Institute

\section{Source}

National Cancer Institute. Sublingual Powder Dosage Form. NCI Thesaurus. Code C149956.

Solid preparation consisting of a powder intended for sublingual use. 